\title{
Dor Mielopática Pós-trauma Raquimedular: Manejo Clínico e Cirúrgico
}

Silvia Mazzali Jorge de Souza *

A dor mielopática é um tipo de dor central que se origina após lesão completa, incompleta ou subclínica das vias somatosensoriais, especialmente do trato espinotalâmico.

Sua incidência varia enormemente $(5-94 \%)^{(1)}$. Acomete a área em que a sensibilidade está comprometida, aparecendo meses ou anos após a lesão.

A dor é descrita como uma sensação de amortecimento desagradável, queimor ou "formigamento", freqüentemente de caráter constante, podendo apresentar períodos de exacerbação. Ocasionalmente são descritos dois tipos distintos de dor, uma de caráter crônico constante e outra intermitente e intensa com distribuição radicular ou por dermátomo, com característica de "choque". Freqüentemente este segundo tipo de dor está associado a comprometimento radicular concomitante ao comprometimento medular ou está localizado no nível da lesão medular, na área de transição da zona de sensibilidade normal para a comprometida.

Os pacientes correlacionam a piora da dor à presença de escara, espasticidade, disfunções do aparelho gênito-urinário e gastro intestinal, estresse psíquico e emocional, mudança de temperatura e umidade ambiental, atividade física, barulho e vibração excessivos.

A dor geralmente é de aparecimento espontâneo. Sua melhora está relacionada à administração de drogas barbitúricas e não às opiáceas ${ }^{(3)}$.

Poderemos encontrar alterações distróficas simpáticas no território da lesão, o que auxilia a perpetuação da dor. Pacientes com quadro de dor crônica geralmente apresentam alterações do humor, comportamento e intelecto.

A dor mielopática pode aparecer após lesão medular completa ou incompleta, cervical, torácica ou lombossacra. Aparentemente as dores mais incapacitantes parecem acompanhar as lesões incompletas ${ }^{(2)}$. Entretanto, segundo Bonica "o desenvolvimento de dor central corresponde a uma idiossincrasia individual, de tal forma que nem todas as pessoas com aparentemente o mesmo tipo de lesão desenvolverão a dor"(3).

Sua etiologia é desconhecida. Uma vez desencadeada, entretanto, parece promover uma cadeia de eventos tálamo- 
corticais, com reorganização sinóptica e alterações de circuitos neurais, que se perpetuam num ciclo, independente da recuperação somato-sensorial.

$\mathrm{Na}$ avaliação de um paciente com dor mielopática pós-trauma raquimedular deveremos descartar situações desencadeantes que devem ser manejadas cirurgicamente, a saber: instabilidade do foco de fratura, estreitamento do canal vertebral, seringomielia, espondilolistese, deslocamento das hastes de fixação.

Deve ser determinado o grau de incapacidade para a realização das atividades de vida prática (AVP), laborativa e social resultante da dor mielopática.

O paciente deverá ser atendido num centro especializado por uma equipe multiprofissional formada por médicos, fisioterapeuta, terapeuta ocupacional, enfermeiro, psicólogo, orientador profissional e nutricionista. A equipe será coordenada por um médico, cuja característica principal será a ordenação das informações recebidas dos diversos setores, sua análise e a programação do tratamento. No manejo da dor, diversas especialidades médicas trabalham em cooperação, a saber médico fisiatra, neurologista, anestesista, neurocirurgião e psiquiatra. A coordenação da equipe caberá àquele que reuna a capacidade de visão global do quadro do paciente associado à habilidade de coordenar uma equipe multiprofissional.

O programa visa diminuir a intensidade da dor ao mínimo possível, visto que sua remissão completa na maioria das vezes não é possível; possibilitar a independência nas AVPs, a reintegração social e laborativa do paciente, garantindo-lhe qualidade de vida.

\section{Tratamento Medicamentoso}

O primeiro passo no tratamento do paciente com dor mielopática é garantir o bem-estar físico e psicossocial do paciente através de cuidados com sua condição física geral e desordens psiquiátricas. Fatores cognitivos e emocionais negativos estão associados a agravamento da intensidade da dor ${ }^{(6)}$.

A escolha da medicação está associada à presença de fatores associados, como síndrome miofascial, dor de caráter radicular e espondilogênico.

\section{Analgésicos Antiinflamatórios não-esteróides (AINH) e Acetaminofen}

$\mathrm{O}$ uso de $\mathrm{AINH}$ requer doses menores do que aquelas utilizadas para o tratamento de processos inflamatórios. $\mathrm{O}$ efeito analgésico é resultado da diminuição da síntese e liberação de prostaglandinas.

A associação simultânea de AINH entre si não resulta em efeito somatório de ação, decorrendo apenas em maior custo e maior incidência de efeitos colaterais ${ }^{(5)}$.

O uso de analgésicos simples e AINH pode ser útil para o tratamento de componentes miofasciais, radiculares e espondilogênicos.

Deveremos empregar sempre as menores doses efetivas, evitar os AINHs com alto nível de recirculação êntero-hepática (comoa indometacina), preferir salicilatos não-acetilados e utilizar protetores da mucosa gástrica em caso de antecedentes gástricos positivos ${ }^{(5)}$.

\section{Antidepressivos}

$\mathrm{O}$ antidepressivo tricíclico tem sido a droga mais eficaz no tratamento da dor mielopática ${ }^{(4)}$.

Acredita-se que seu efeito deva-se à diminuição da recaptação de mono aminas, principalmente a serotonina e a noradrenalina, da fenda sináptica. Dos triciclos a amitriptilina e a imipramina são as que mais fortemente inibem esta recaptação. A fluxetina (PROZAC®) também apresenta esta característica, porém seu papel no controle da dor ainda deverá ser determinado ${ }^{(5)}$.

As doses e propriedades dos antidepressivos são apresentados na tabela 01.

Os antidepressivos são mais eficazes no controle da dor constante, tipo queimor ou amortecimento desagradável.

Contribuem no tratamento da depressão freqüentemente associada à dor crônica, por apresentarem aspectos neuroquímicos superpossíveis $^{(7)}$.

\section{Anticonvulsivantes}

Têm seu papel no tratamento da dor intermitente, tipo choque, que resulta geralmente de um comprometimento radicular.

Seu mecanismo de ação está relacionado à supressão de descargas neurais anormais, visa seu efeito na condução de sódio(4). Os anticonvulsivantes mais utilizados são: carbamazepina, ácido valpróico, difenil-hidantoína, clonazepan e fenitoína.

A carbamazepina é o mais usado. Deveremos monitorizar as enzimas hepáticas (que não devem ultrapassar 3 vezes o valor normal) e a função da medula óssea. No geral chega-se até a dose de $600 \mathrm{mg} /$ dia.

A associação dos antidepressivos com os anticonvulsivantes é mais bem sucedida que o uso isolado dos últimos ${ }^{(4)}$. 


\section{Outras Medicações}

Baclofen, um potente agonista -GABA, tem seu papel coadjuvante naqueles casos em que a espasticidade constitui um fator perpetuante do quadro doloroso.

Os fenotiozínicos parecem potencializar o efeito dos antidepressivos tricíclicos, por inibição da sua degradação, elevando seus níveis séricos. Seu efeito ansiolítico e sedativo contribui para a melhora do quadro álgico ${ }^{(7)}$.

\section{Infusão Intratecal de Morfina}

A infusão contínua de morfina no espaço intratecal parece ser uma alternativa segura e importante no manejo da dor central ${ }^{(11)}$.

O aparecimento de tolerância e dependência não é significativo frente às baixas doses administradas de forma contínua através de uma bomba de infusão implantada no subcutâneo do paciente.

Os resultados têm sido promissores no controle da dor daqueles pacientes com expectativa de vida prolongada ${ }^{(11)}$. Novas drogas vêm sendo pesquisadas, como a somatostina, clonidina, encefalinas e midazolam, porém não estão ainda disponíveis para uso clínico.

No nosso meio, esta técnica está ainda restrita aos grandes centros de maior poder aquisitivo, devido ao custo elevado das bombas de infusão.

\section{Tratamento Cirúrgico Neurólise Química e Rizotomias}

Estes procedimentos comumente não beneficiam pacientes com dor mielopática ${ }^{(7)}$. Bloqueio anestésico proximal local pode promover alívio temporário em até $85 \%$ dos casos ${ }^{(3)}$.

Bonica acredita que a simpatectomia deva se limitar aos casos em que houver sinais e sintomas de distrofia simpática.

A neurólise química poderá ser realizada em casos de dor lancinante pós-lesão de raízes sacrais baixas e coccígeas, em que não se precisa preservar a inervação vesical e intestinal ${ }^{(3)}$.

\section{Cordotomia e Cordectomia}

Jacobsen afirma que a mielotomia transversa realizada 2 a 3 segmentos acima daquele em que a lesão está presente pode aliviar a dor intermitente, lancinante, radicular.

O procedimento está mais bem estabelecido para os casos de lesão incompleta de cone medular e cauda eqüina, em que a melhora pode chegar a $70 \%$ dos $\operatorname{casos}^{(3,7)}$.

\section{DREZ}

A lesão da zona de entrada da raiz dorsal (DREZ) está mais bem indicada para pacientes com

TABELA 1: ANTIDEPRESSIVOS

\begin{tabular}{|c|c|c|c|}
\hline DROGA & $\begin{array}{l}\text { EFEITO } \\
\text { SEROTONINÉRGICO }\end{array}$ & $\begin{array}{l}\text { EFEITO } \\
\text { ANTICOLINÉRGICO }\end{array}$ & $\begin{array}{l}\text { DOSE } \\
(\mathrm{mg})\end{array}$ \\
\hline $\begin{array}{l}\text { Aminas Terciárias } \\
\text { Amitriptilina } \\
\text { Imipramina } \\
\text { Doxepin }\end{array}$ & $\begin{array}{l}\text { Forte } \\
\text { Forte } \\
\text { Leve }\end{array}$ & $\begin{array}{l}\text { Forte } \\
\text { Leve } \\
\text { Leve }\end{array}$ & $\begin{array}{l}10-200 \\
10-200 \\
10-150\end{array}$ \\
\hline $\begin{array}{l}\text { Aminas Secundárias } \\
\text { Nortriptilina } \\
\text { Protriptiline } \\
\text { Desipramine } \\
\text { Amoxapine }\end{array}$ & $\begin{array}{l}\text { Moderada } \\
\text { Leve } \\
\text { Leve } \\
\text { Leve }\end{array}$ & $\begin{array}{l}\text { Leve } \\
\text { Moderado } \\
\text { Leve } \\
\text { Moderado }\end{array}$ & $\begin{array}{l}10-100 \\
5-40 \\
25-200 \\
50-300\end{array}$ \\
\hline $\begin{array}{l}\text { Triazolopiridine } \\
\text { Trazodone }\end{array}$ & Moderado & Leve & $50-200$ \\
\hline $\begin{array}{l}\text { Biciclico } \\
\text { Fluoxetine }\end{array}$ & Forte & Leve & 20 \\
\hline
\end{tabular}


dor originada de avulsão de raízes do plexo braquial.

Aparentemente aqueles pacientes que se beneficiam da cordotomia seriam candidatos para a DREZ ${ }^{(3)}$.

\section{Outros Procedimentos}

A estimulação elétrica crônica da medula espinal pode trazer alívio para até $50 \%$ dos pacientes com dor mielopática de origem traumática ${ }^{(3,7)}$. Costuma-se fazer um teste prévio à instalação definitiva dos eletrodos de estimulação no funículo posterior.

A melhor resposta se obtém nos casos de lesão incompleta, pois nestes não há degeneração significante do funículo posterior ${ }^{(7)}$.

O objetivo do procedimento é provocar uma sensação parestésica na parte comprometida do corpo, desta forma suprimindo hiperatividade neural patológica responsável pela dor ${ }^{(3)}$.

Dados sugerem que apesar desta técnica dever ser sempre tentada, após 1 ano de acompanhamento, apenas $20 \%$ dos doentes continuam com o quadro álgico controlado ${ }^{(8)}$.

\section{TENS}

A estimulação elétrica transcutânea tem uso limitado na dor central devido à sua influência limitada no quadro geral da síndrome de dor crônica ${ }^{(3)}$.

\section{Conclusão}

O manejo da dor mielopática do paciente lesado medular deve ser realizado por uma equipe multiprofissional, coordenada por um profissional médico com visão abrangente das múltiplas possibilidades terapêuticas.

O tratamento deve ser iniciado pela conduta mais simples e menos invasiva, sendo posteriormente reavaliado e ajustado conforme as respostas terapêuticas do paciente.

O paciente deve estar consciente do conceito e da origem da dor mielopática, bem como das múltiplas possibilidades terapêuticas, de forma a acompanhar, sem ansiedade, seu tratamento.

O melhor tratamento será aquele que promover o maior alívio da dor, garantindo o bemestar físico e social para o paciente.

\section{Referências Bibliográficas}

1. LOUBSER, P.G. et. al. Evaluation of Central Spinal Cord Injury Pain with Diagnostic Spinal Anesthesiology 79 (2): 1993.

2. BERIC, A. Central Pain: New Syndromes and their Evaluation. Muscle and Nerve. 16: 1017-1024, 1993.

3. TASKER, R.R. Pain Resulting from Central Nervous System pathology (Central Pain). In: Lea and Febiger (eds): The Managemente of Pain. Philadelphia, vol I, 264-275, 1990.

4. SANDFORD, P.R. et. al. Amitriptyline and Larbamazepine in the Treatment of Dysesthetic Pain in Spinal Cord Injury. Aarch. Phys. Med. Rehabil.75: 300-1, 1992.

5. DEAN,B. Z.et. al. Pain Rehabilitation. Therapeutic Options in Pain Management. Arch Phys Med Rehabil 75: 5-21, 1994.

6. SUMMERS, J.D. et. al. Psychosocial Factors in Chronic Spinal Cord Injury pain.Pain. 47: 183-189, 1991.

7. JACOBSEN, M.J. A Lesão do Trato de Lissauer e do Corno Posterior de Substância Cinzenta da Medula Espinal e a Estimulação do Sistema Nervoso Central para o Tratamento da Dor por Desaferentação. In: Tese de Doutorado Apresentada à Faculdade de Medicina da USP, São Paulo, 1990.

8. RICHARDSON, R.R. et. al. Neurostimulation in the modulation on of intractable paraplegia in traumatic neuroma pains. PAIN. 8 : 75-84, 1980.

9. SIE, I.H. et. al. Upper Extremity Pain in the Postrehabilitation Spinal Cord Injured Patient. Arch. Phys. Med. Rehabil. 73: 44, 1992.

10. Loeser, J.D. et. al. Interdisciplinary, Multimodal Management of Chronic Pain. In:The Managemente of Pain. Philadelphia, vol II, 2107, 1990

11. FENOLLOSA, P. et. al. Chronic pain in the Spinal Cord Injured: Statistical Approach and Pharmacological Treatment. Paraplegia. 31: 722-729, 1993. 